\title{
A importância do planejamento estratégico associado à utilização de ferramentas de controle para maximização da lucratividade em confinamento de gado de corte
}

Importance of strategic planning associated with the use of control tools for maximizing profitability in beef cattle feedlot

\author{
Stefan Braren Damato ${ }^{*}$; Suzana Eri Yotsuyanagi²
}

\footnotetext{
${ }^{1}$ I-PECEGE, Especialista em Agronegócios - Rua Alexandre Herculano 120, sala T4, Vila Monteiro - CEP 13418-445 Piracicaba (SP), Brasil

${ }^{2}$ Centro de Tecnologia de Carnes, Instituto de Tecnologia de Alimentos - Av. Brasil, 2280. Jardim Chapadão - Campinas, São Paulo, Brasil
}

\section{Resumo}

O mercado de confinamento demonstra alto grau de complexidade quanto às variáveis que $o$ influenciam, gerando dificuldade no estabelecimento de diretrizes estratégicas para a atividade. A necessidade de gerar milhares de simulações de resultados para que se tornasse possível uma visão ampla de negócios levou à criação de uma ferramenta que cruzasse a maior quantidade possível de dados técnicos e mercadológicos, concatenasse as informações disponíveis e retornasse cenários de forma direta ao gestor, possibilitando a este, a determinação de objetivos e estratégias que aumentariam a competitividade da empresa. Para tanto, foi estudado um confinamento no estado de Goiás, em que foram obtidas informações reais de produção e resultados financeiros no ano de 2012. Foram comparados cenários reais e simulados, com a finalidade de se comparar o EBITDA, além de ser apresentada uma breve explanação sobre os fatores que tem direta influência sobre os cálculos realizados. Os estudos demonstram que a utilização de um plano estratégico pode contribuir positivamente para a lucratividade ao responder o melhor momento de confinar, o perfil dos animais, e o período ideal de manutenção no regime de engorda. Por questão de confidencialidade empresarial, não foi autorizada a divulgação da fonte dos dados.

Palavras-chave análise de mercado, controladoria, planejamento estratégico

\begin{abstract}
The containment market shows a high degree of complexity for the variables that influence it, hindering the establishment of strategic guidelines for the activity. The need to generate thousands of simulating results to obtain a broad vision of the business has led to the creation of a tool that crossed the largest possible amount of market and technical data, concatenating information available and developing scenarios directly to the manager, providing tools to determine objectives and strategies to increase company's competitiveness. For that purpose, a feedlot in the state of Goiás (Brazil) was studied, where actual information of production and financial results in the year 2012 were obtained. Actual and simulated scenarios were compared to apply EBITDA (earnings before interest, taxes, depreciation and amortization). A brief explanation of factors that directly influenced the calculations was also presented. Studies show that the use of a strategic plan can contribute positively to profitability by showing the best time to confine, animals' profile, and ideal period to keep animals in the fattening system. Due to business confidentiality, the source of the data was not allowed to be disclosed.
\end{abstract}

Keywords: accounting, strategic planning, market analysis

\footnotetext{
* Autor correspondente <stefanbdamato@hotmail.com> Enviado: 19 dez. 2014 Aprovado: 25 fev. 2015
} 


\section{Introdução}

Segundo relatório da Food and Agriculture Organization of the United Nations FAO intitulado "World Agriculture towards 2030/2050", a população mundial deverá atingir 9,5 bilhões de indivíduos até o ano de 2050 e a taxa de crescimento de demanda por produtos agrícolas deve atingir a média de 1,1\% ao ano, elevando substancialmente a necessidade de ampliação de oferta (Alexandratos et al., 2012).

O mesmo relatório indica que evidências históricas sugerem que o crescimento da agricultura tem sido suficiente para atender a escalada da demanda até pouco tempo, antes do recente surgimento dos biocombustíveis e a demanda adicional gerada por eles. Na realidade, a agricultura mundial existiu por muitas décadas em um ambiente de demanda reprimida, em que milhões de pessoas por falta de condições financeiras não podiam adquirir alimentos e estimular a demanda.

A visão econômica indica que a pobreza continuará a existir a médio prazo, portanto, o indicativo é que para uma parcela significativa da população a demanda potencial de alimentos não será expressa totalmente como a demanda efetiva.

Partindo do pressuposto econômico de oferta e demanda, é possível dizer que uma maior oferta de alimentos geraria a redução nos preços e causaria a abertura desta demanda suprimida. Para isto, é preciso ampliar a produção total de alimentos e, dentre as fronteiras agrícolas disponíveis, as áreas de pastagens são comumente citadas. Uma parcela significativa poderia ser cedida à agricultura sem que houvesse redução na produção de carne bovina, uma vez que há possibilidade de ganho em produtividade através da intensificação da atividade, sendo a engorda em confinamento um importante meio de produção neste sentido.

Como característica, esta é uma atividade que possui elevado risco causado por efeitos ambientais e seus impactos em questões sanitárias, alta demanda de capital e conhecimento técnico, baixa padronização genética - com consequência no desenvolvimento zootécnico, e elevado risco às variações de mercado.

No confinamento em questão, o processo de compra de animais para engorda é iniciado com uma projeção de resultados esperados ao término do período de engorda de cada lote adquirido e, as aprovações de compras dependiam dos resultados futuros previstos. Contudo, o grande número de variáveis que devem ser consideradas para que sejam obtidos resultados satisfatórios dificulta o estabelecimento de estratégias de compra de animais e o planejamento de cenários além de um ciclo de produção.

No ano de 2012 a atividade de confinamento na fazenda objeto do estudo apresentou prejuízo, mas foi notado que não havia pleno conhecimento sobre o que 
haveria causado tal resultado, uma vez que todas as simulações de compra de animais haviam se apresentado viáveis. Foi observado então que o conhecimento de ordem técnica era dominado por grande parte dos elos da cadeia produtiva, contudo, o entendimento de mercado e o planejamento eram áreas ainda pouco exploradas e, consequentemente, poderiam resultar em riscos significativos.

Portanto o objetivo do trabalho foi questionar se o sucesso da atividade careceria de uma visão mais ampla e de longo curso, se a determinação de diretrizes estratégicas internas e externas embasadas por um profundo conhecimento do mercado poderia gerar escolhas que mudassem o curso dos resultados. Se sim, qual poderia ser o impacto da adoção de estratégias além de um ciclo de produção e, se a utilização das ferramentas de proteção seria suficiente para minimizar o risco de mercado a um ponto em que o risco principal da atividade seja de ordem zootécnica.

\section{Material e métodos}

\section{Características do Confinamento}

O confinamento está localizado no estado de Goiás, com capacidade estática no período de máxima lotação superior a 20.000 cabeças e próximo a um abatedourofrigorífico. A atividade é realizada durante todo o ano, com intensificação no período seco do ano (maio a outubro) e utiliza subprodutos agrícolas disponíveis na praça como forma de redução de custos, especialmente substitutivos à soja.

Possui uma estrutura descentralizada em que os gestores principais não se localizam no sítio, havendo a necessidade de trocas de informações e relatórios. Esta distância física dificulta a tomada de decisão da alta diretoria, pois muitas avaliações ainda são empíricas e dependem de avaliação visual, motivo pelo qual o trabalho da controladoria é crítico e um bom plano estratégico para a equipe tática é fundamental.

Não há sistema de controle de informação, o trabalho de controladoria está restrito a planilhas complexas de Excel, que assume posição de alto risco quanto à segurança e qualidade das informações e baixa agilidade na geração e transmissão da mesma.

\section{Simulação de cenários futuros}

Um ciclo de produção na unidade produtiva estudada possui em torno de 90 a 100 dias, condicionado ao desempenho dos animais e pesos de entrada e saída. 
Toda a simulação realizada para a aquisição de animais visava apenas a lotação dos currais, sem que houvesse uma estratégia consistente além do ciclo corrente de produção. O comprador de gado tinha como objetivo buscar animais no mercado, mas sem diretrizes específicas traçadas.

O processo de confinamento de animais é extremamente crítico quanto à decisão do momento ideal de retirada dos animais do sistema de engorda e sua destinação para abate. A eficiência biológica não possui aspecto linear, uma vez que esta tende a ter uma fase de crescimento acentuado, uma estabilização e, um declínio.

Garantir a máxima rentabilidade da atividade significa enviar os animais para abate quando as curvas de custo e receita atinjam máximo descolamento (Figura 1). Observar o ponto ideal é subjetivo quando não há controle preciso no fornecimento de ração, uma vez que a melhor forma de se precisar o ponto ideal de retirada dos animais é quando há o declínio na ingestão de matéria seca (desde que esta não esteja ocorrendo por distúrbios metabólicos ou ambientais).

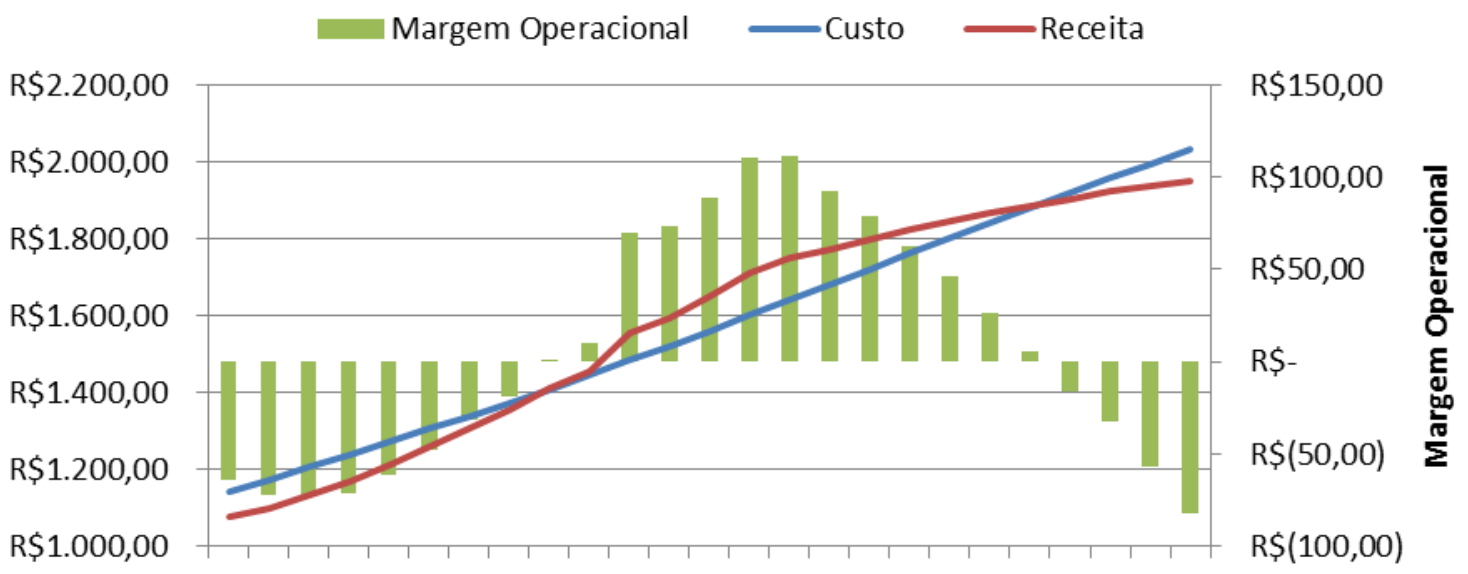

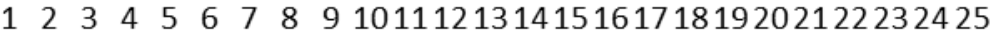

Semana

Figura 1. Variação da rentabilidade ao longo do tempo Fonte: Dados de Pesquisa

Além da percepção quanto à ingestão de matéria-seca, é preciso considerar também premiações que o confinamento pode obter ao atingir determinadas exigências do frigorífico - especialmente premiação Trace List, bem como observar flutuações na cotação da arroba bovina. Estes têm influência direta sobre o faturamento e podem promover um forte deslocamento na curva. 
A rentabilidade é influenciada tanto por fatores internos (critérios técnicos e estrutura de custos administrativo-operacionais) como fatores externos (mercado).

Internos: peso de entrada; peso de saída; ganho médio diário (kg de peso vivo); ingestão de matéria-seca (proporcional ao peso vivo); rendimento de carcaça; conversão alimentar (kgMS/kgPV); balanceamento de ração; custos fixos e administrativos; custo frete, ICMS, medicamentos, rastreabilidade, comissões, GTA; custo de oportunidade.

Externos: cotações da arroba; custo com ração (R\$/kgMS); premiações aplicadas.

Frente ao exposto, a simulação de resultados é gerada buscando responder às seguintes perguntas: Qual o peso de entrada ideal para os animais a fim de garantir a máxima rentabilidade no período analisado? É mais eficiente comprar os animais, ou trabalhar em regime de parceria? Quantos dias os animais deverão ficar confinados para atingir a máxima rentabilidade?

Os modelos de negociação

Aquisição de animais

A aquisição de animais magros para engorda era realizada através da utilização da última cotação CEPEA Rio Verde multiplicado pelo peso vivo dos animais pesados na fazenda e um rendimento de carcaça de $50 \%$. Todos os custos envolvidos na movimentação dos animais até a fazenda cabia ao confinamento.

\section{Parceria}

No modelo de parceria, os pecuaristas interessados enviavam os animais para o confinamento e teriam o acerto financeiro calculado com a cotação da arroba CEPEA Rio Verde 90 dias após a entrega dos animais. Os animais eram pesados na balança do confinamento e, os pecuaristas recebiam um rendimento de carcaça de $52 \%$, a fim de cobrir a quebra de peso no transporte.

Este modelo apresentava vantagem competitiva para ambos os lados, pois reduziria o impacto no fluxo de caixa e consequentemente nos juros, e também ao pecuarista, que utilizaria o confinamento como armazém dos animais, podendo inclusive negociar através do confinamento suas arrobas no mercado futuro para minimizar os riscos da atividade. 


\section{Metodologia de cálculo}

Diversos cenários para cada uma das semanas do ano são gerados com o intuito de que seja obtido aquele de maior rentabilidade. São alternados os métodos de negociação (compra ou parceria), praça (aproveitamento de uma possível arbitragem), peso de entrada e período de confinamento.

Estas informações possibilitam buscar em um banco de dado as informações técnicas necessárias para cada faixa de peso de entrada e saída, bem como também as cotações no mercado futuro do boi gordo. Uma vez estimado o desempenho dos animais e a expectativa de preços de compra e venda, é possível prever a tendência de lucratividade da atividade.

O EBITDA será obtido pela subtração do faturamento bruto de todos os demais custos envolvidos na operação (aquisição de animais, frete, ração, medicamentos, GTA, brincos, trace list, custos operacionais e administrativos) e o custo de oportunidade, que foi estimado em $1 \%$.

\section{Amostra}

Para os dados zootécnicos, foram obtidos dados de 54.242 animais com diferentes faixas de pesos de entrada, características raciais e sexos. Destes, foram filtrados apenas animais zebuínos (predominância de animais Nelore), machos inteiros, com peso de entrada variando entre 240 e $440 \mathrm{~kg}$, restando uma amostra total de 33.548 animais (Tabela 1).

Exceto pelo rendimento de carcaça, que é correlacionado ao peso dos animais ao serem abatidos, todos os demais indicadores foram indexados às faixas de pesos de entrada.

Tabela 1. Amostragem por faixa de peso

\begin{tabular}{cc}
\hline Peso de Entrada & Tamanho da Amostra \\
\hline kg & cabeça \\
240 a 300 & 3.051 \\
301 a 330 & 6.722 \\
331 a 360 & 8.751 \\
361 a 390 & 8.653 \\
390 a 410 & 4.417 \\
410 a 440 & 2.224
\end{tabular}




\section{Peso de entrada}

O peso de entrada dos animais é uma das variáveis mais importantes, isto porque o custo de aquisição dos animais é realizado baseado em seu peso vivo e, é um fator determinante para o estabelecimento do período que os animais deverão permanecer confinados.

No momento da aquisição, todas as simulações são realizadas exclusivamente utilizando o peso vivo dos animais, visto que a base de dados de resultados é estratificada através de faixas de peso (Tabela 1).

\section{Peso de saída}

O peso de saída (Tabela 2) é o objetivo final esperado que os animais devam atingir ao final de seu período de confinamento. Este objetivo costuma ser variável e respeita o desempenho técnico dos animais, o valor de mercado da arroba, tratativas comerciais entre o confinamento e o frigorífico, premiação Trace List.

Tabela 2. Peso de Saída e Período de Permanência dos animais confinados

\begin{tabular}{cccc}
\hline Estratificação & Peso de entrada & Peso de Saída & Dias de Confinamento \\
\hline kg & $\mathrm{kg}$ & $\mathrm{kg}$ & \\
241 a 300 & 286 & 467 & 137 \\
301 a 330 & 316 & 489 & 109 \\
331 a 360 & 345 & 507 & 100 \\
361 a 390 & 373 & 527 & 95 \\
391 a 410 & 399 & 545 & 94 \\
411 a 440 & 420 & 557 & 89 \\
\hline
\end{tabular}

Desempenho técnico: A negociação de compra de animais magros no Brasil é realizada em aspectos empíricos dos compradores de gado, onde não são empregados equipamentos ou metodologia científica para avaliação de rebanhos comerciais. Desta forma, é comum que os avaliadores cometam enganos e, animais que foram avaliados com capacidade de atingir determinado peso, ao atingirem peso inferior já tenham atingido o ponto de máxima produtividade e precisem ser abatidos.

Valor de mercado da arroba: A variação diária de cotações impacta na tomada de decisão sobre o abate, isto porque picos de alta ou baixa podem influenciar na tomada de decisão, ainda que os animais tenham potencial para ganho de peso, o 
gestor pode optar por abater tais animais em uma semana em que o valor da arroba negociada compense a perda de arrobas potenciais.

Tratativas comerciais entre o confinamento e o frigorífico: Havia um forte estreitamento entre o frigorifico e o confinamento devido a anos de negócios conjuntos, isto gerava demandas específicas do frigorífico junto ao confinamento por padrões especiais desejados para atender mercados específicos. Tais demandas exigem, em geral, maior tempo de cocho dos animais, para que estes produzam cortes maiores e com maior cobertura de gordura. A deposição de gordura é um processo mais lento e caro do que o crescimento muscular dos animais, o que leva o frigorífico a oferecer premiações especiais.

Premiação Lista Trace: Trade Control and Expert System - TRACE é uma rede europeia de notificação, certificação e monitoramento veterinário para produtos de origem animal (EUROPEAN COMISSION, 2007-2013). Esta utiliza a lista Estabelecimento Rural Aprovado SISBOV - ERAS para definir as fazendas aptas a exportar carne para a união europeia. As fazendas aprovadas que devem manter registro atualizado de todos os animais na Base Nacional de Dados - BND. Estes devem permanecer comprovadamente pelo menos 90 dias em área habilitada (propriedade que conste na lista ERAS) e 40 dias na última propriedade. Caso atendidas as exigências, o frigorífico premiava o confinamento com um bônus de $R \$ 3,00$ por arroba. Esta premiação levava o confinamento a muitas vezes adiar o envio dos animais para abate, pois na prática, a maior parte dos animais adquiridos não estava previamente em área habilitada e necessitavam permanecer pelo menos 90 dias confinados.

\section{Rendimento de Carcaça}

Entende-se por carcaça o animal abatido, sangrado, esfolado, eviscerado, desprovido de cabeça, patas, rabada, glândula mamária (fêmea), verga, exceto suas raízes, e testículos (macho), rins, gordura peri-renal e inguinal, ferida de sangria, medula espinhal, diafragma e seus pilares (BRASIL, 1990).

O rendimento de carcaça (Tabela 3 ) é a relação entre o peso de carcaça e o peso vivo do animal. Segundo o rendimento é afetado pelo tipo de dieta e o período em jejum, podendo variar de 10 a $20 \%$ em função do sistema de alimentação (Jorge et al, 1997).

O rendimento de carcaça também é variável com o peso ao abate e o grau de engorda de maneira positiva (Preston et al., 1970). Portanto, é de se esperar que animais mais pesados e com melhor acabamento apresentem maiores rendimentos. 
Há ainda uma variável muito importante, que é a operação da indústria. Dentro da sala de abate, existem operações (desnuca, retirada da cauda, sangria, gordura, diafragma) críticas que, haja dolo ou não, os operadores tem capacidade de influenciar fortemente no rendimento. Existe motivação da indústria para reduzir o rendimento de carcaça, pois a carne e gordura retiradas no abate serão comercializadas e geram uma fonte de renda isenta de custo de aquisição. Graças ao histórico de longa data existente entre o confinamento e o frigorífico, este tipo de prática não era observado.

Tabela 3. Rendimentos de Carcaça

\begin{tabular}{cccc}
\hline $\begin{array}{c}\text { Estratificação } \\
\text { kg }\end{array}$ & $\begin{array}{c}\text { Amostragem } \\
\text { cabeça }\end{array}$ & $\begin{array}{c}\text { Peso Saída } \\
\mathrm{kg}\end{array}$ & $\begin{array}{c}\text { Rendimento de Carcaça } \\
\%\end{array}$ \\
\hline 440 a 460 & 1.387 & 451,65 & 55,1 \\
461 a 480 & 3.874 & 472,59 & 56,1 \\
481 a 500 & 7.057 & 490,30 & 55,4 \\
501 a 520 & 7.433 & 508,35 & 55,0 \\
521 a 540 & 5.470 & 528,85 & 54,9 \\
541 a 560 & 4.858 & 549,11 & 55,0 \\
$561>$ & 3.431 & 575,20 & 55,4 \\
\hline
\end{tabular}

\section{Ganho Médio Diário}

O ganho de peso médio diário é o quanto um animal eleva seu peso vivo diariamente dentro do sistema de confinamento. Este aumento de peso por si não traduz a eficiência do sistema produtivo. É preciso ainda associar a ingestão de matéria seca e o rendimento de carcaça, que juntos determinam a eficiência biológica dos animais confinados (kgMS/arroba carcaça), isto é, quanto de ração é preciso fornecer para que os animais a converta em carcaça. Apesar de não ser o indicador perfeito de rentabilidade, ele é de fundamental importância para que seja possível estimar a movimentação dos animais e a expectativa de faturamento.

Tanto quando eram realizadas as balizas de compra de animais quanto no confinamento, era estimado um ganho de peso diário linear. Este tipo de aplicação pode conduzir o gestor a uma avaliação equivocada quanto a rentabilidade e fluxo de movimentação de animais. 
A Figura 2 demonstra um gráfico que animais que ao final de um mesmo período tenham em média um mesmo ganho de peso, há forte oscilação quanto ao ganho de peso dos animais, especialmente após a décima quinta semana.

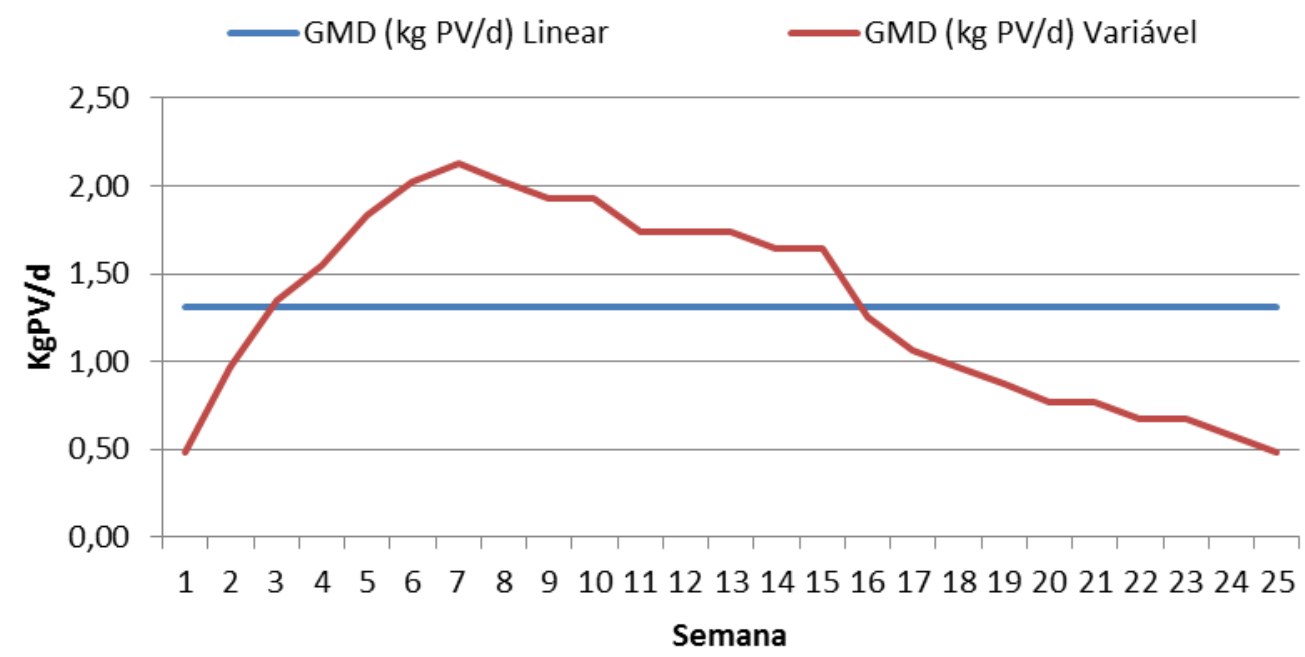

Figura 2. Ganho médio diário ao longo das semanas para machos da raça Nelore

\section{Ingestão de Matéria Seca}

Ingestão de matéria seca é a quantidade de alimento (excluindo a umidade) ingerido pelos animais. Este indicador está diretamente relacionado à rentabilidade, uma vez que representa $24 \%$ do custo dos produtos vendidos e $82 \%$ do custo diário de manutenção dos animais no cocho.

A diminuição de ingestão de matéria seca pelos animais traz resultados diretos na diminuição do desenvolvimento dos mesmos, pois a maior parte dos nutrientes da dieta é utilizada para suprir as exigências de mantença. Pequenas alterações no consumo de alimentos podem ocasionar limitações na eficiência dos processos produtivos, e consequentemente, a taxa de crescimento irá diminuir; o potencial genético, para ganho de peso não será alcançado e a lucratividade da atividade pecuária estará comprometida (Azêvedo et al., 2010). Fatores metabólicos ou sanitários podem afetar os animais individualmente, enquanto que fatores ambientais podem reduzir o consumo generalizado dos animais (EMBRAPA).

Para a predição de consumo, foi utilizada a equação descrita por (Azêvedo et al., 2010) em que o consumo de matéria seca - CMS em zebuínos pode ser estimado 
utilizando o peso vivo médio do animal - PVM e o ganho médio diário do mesmo, conforme na equação (1).

$$
C M S=-2,7878+0,08789 P V M^{0,75}+5,0487 G M D-1,6835 G M D^{2}
$$

Onde, CMS: consumo matéria seca; PVM: peso vivo médio do animal; GMD: ganho médio diário.

Esta equação gera uma curva (Figura 3) na qual podemos perceber a evolução do consumo ao longo do tempo.

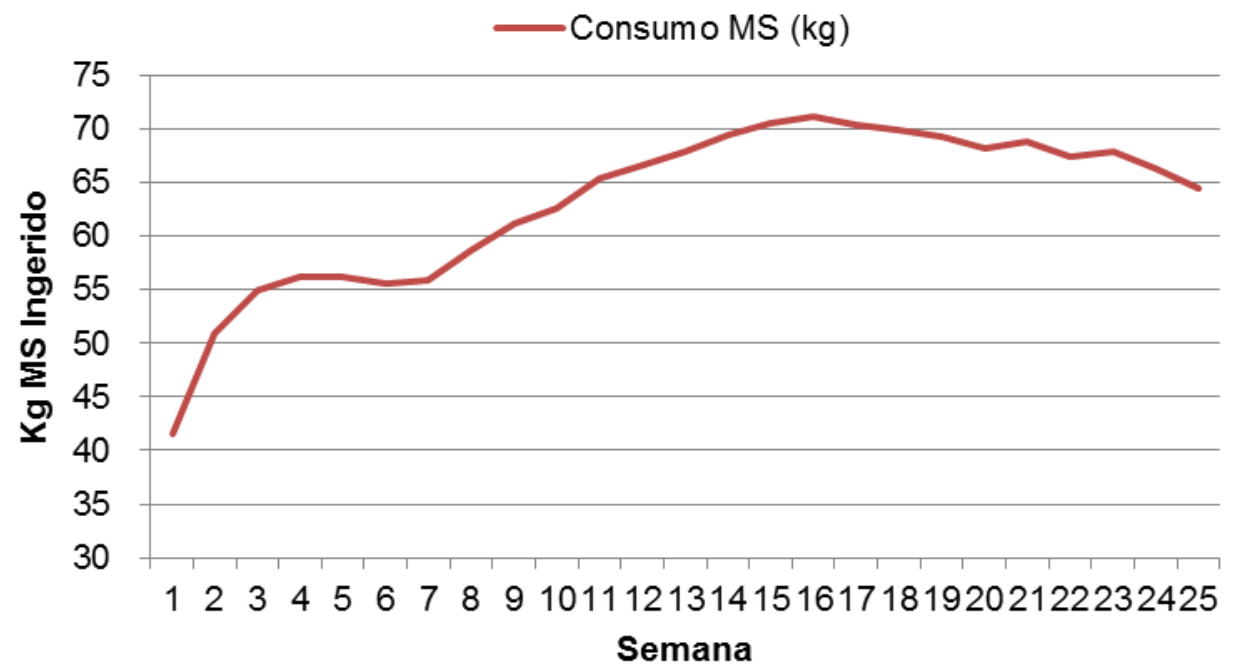

Figura 3. Consumo de Matéria Seca

Fonte: Azêvedo et al., 2010

Custos dos Produtos Vendidos - CPV

Os custos dos produtos vendidos foram abrigados em quatro grupos: entrada, alimentação, administrativo/operacional e custo de oportunidade (Figura 4).

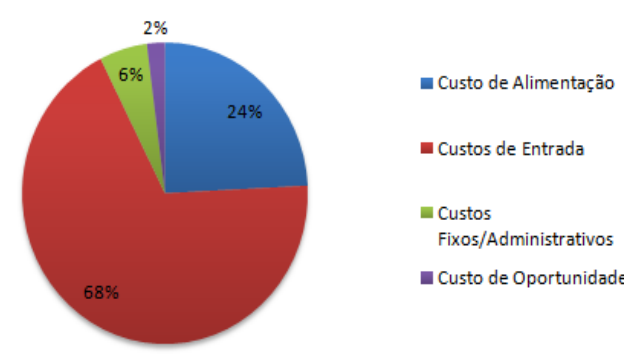

Figura 4. Custo dos Produtos Vendidos

Custo de Entrada: compreende os custos de compra de animais, frete, rastreabilidade (brinco, inserção na BND) e, protocolo sanitário de entrada. Representa 
o principal custo do confinamento com $68 \%$ do total, em que $97 \%$ deste custo é composto pela aquisição dos animais.

Custo de Alimentação: explicita o montante despendido para fornecer o volume total de ração fornecida aos animais durante o período de engorda.

Custo administrativo/operacional: engloba todos os demais custos administrativos e operacionais, tais como: despesas com pessoal, manutenção, viagens, comunicação, etc. Apesar de absorver os custos fixos, afim de não penalizar o resultado operacional dos animais confinados quando a lotação não é máxima, tal custo é padronizado ao longo do ano.

\section{Faturamento}

O faturamento do confinamento é o produto entre o valor da cotação negociado no mercado balcão - somadas premiações, e o peso obtido das carcaças dos animais.

Outra fonte de renda é associada a venda de esterco, mas este não é sempre considerado, vez que é comumente utilizado dentro da própria fazenda para a adubação de lavouras ou pastagens.

Observou-se que no ano de 2012, o confinamento realizou a venda dos animais com uma cotação base (excluídas premiações) 4,33\% baixo do índice CEPEA da região e obteve 3,29\% de premiação - a maior parte desta premiação relacionada ao prêmio de animais possíveis de exportação para União Europeia (Figura 5).

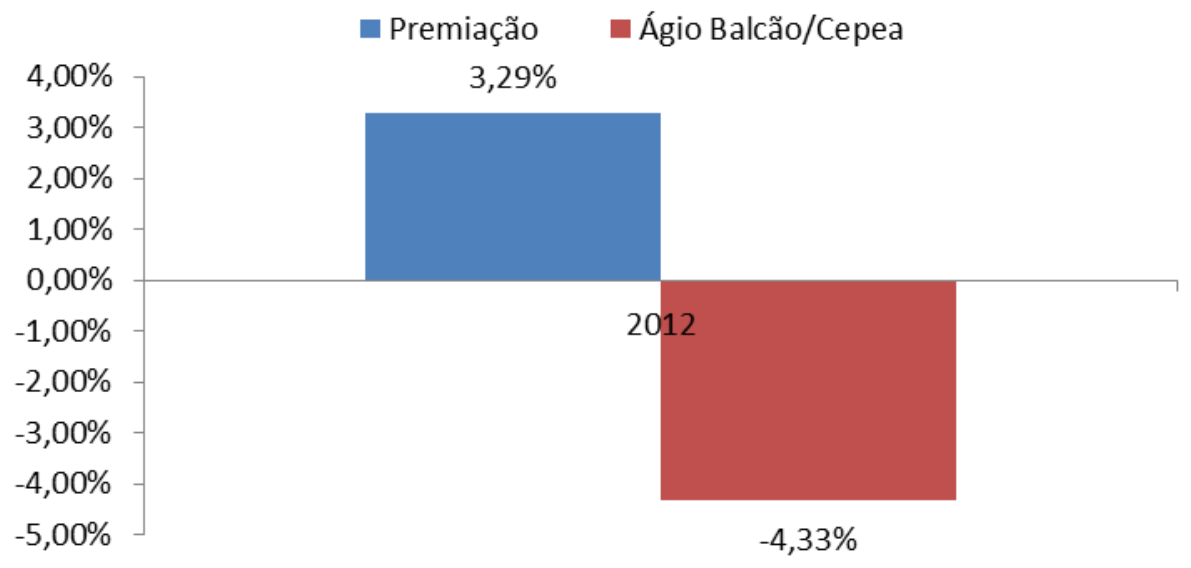

Figura 5. Premiação e ágio recebidos 


\section{Resultados e Discussões}

Da análise crítica e o planejamento estratégico associado ao confinamento estudado

O estudo comparativo se deu em três análises, uma com resultados reais obtidos no ano de 2012, outra que utiliza projeções zootécnicas e cotações de compra e venda no mercado futuro, e a terceira, que cruza os dois cenários para demonstrar como poderia ter sido o resultado caso o plano estratégico caso estivesse implantado.

\section{Resultados Reais 2012}

Apesar de apresentar margem operacional positiva, a atividade foi incapaz de gerar receita suficiente para arcar com os custos fixos, resultando em um prejuízo médio de $R \$ 89,22$ por cabeça no ano de 2012 (Tabela 4).

É recorrente a presença de ágio nas negociações de compra de boi magro $(2,88 \%)$, mas este sobre preço não é responsável pelo resultado negativo, uma vez que a engorda destes animais a um custo de produção inferior ao valor venal irá diluí-lo. $O$ valor da arroba produzida (considerando custo de ração e custos fixos diários) foi de $R \$$ 78,01 ou $19,02 \%$ superior à cotação recebida no momento da venda.

Todavia, para que o break even fosse atingido, teria sido necessário o custo da arroba produzida de $\mathrm{R} \$ 65,19$ - um custo $29,8 \%$ inferior ao valor de mercado.

Os indicadores zootécnicos (ganho de peso, conversão alimentar e rendimento de carcaça) sugerem um bom desempenho dos animais. Resta avaliar o mercado pecuário para o ano de 2012 e as negociações praticadas a fim de elucidar o real motivo pelo resultado aquém do esperado. 
Tabela 4. Resultados Reais 2012

\begin{tabular}{|c|c|c|c|c|c|}
\hline & \multicolumn{4}{|c|}{ Trimestre } & \multirow[b]{2}{*}{2012} \\
\hline & $1^{\circ}$ & $2^{\circ}$ & $3^{\circ}$ & $4^{\circ}$ & \\
\hline Cabeças & 934 & 1.643 & 10.061 & 8.329 & 20.967 \\
\hline Diárias $(\mathrm{R} \$)$ & 110,26 & 100,82 & 96,05 & 95,86 & 96,98 \\
\hline Peso de Entrada (kg) & 335,04 & 357,86 & 348,09 & 343,37 & 346,45 \\
\hline $\begin{array}{l}\text { Cotação Compra / Peso Entrada } \\
\text { (R\$/arroba) }\end{array}$ & 108,74 & 96,02 & 102,31 & 106,50 & 103,74 \\
\hline Peso de Saída (kg) & 511,86 & 534,86 & 516,29 & 480,82 & 503,55 \\
\hline $\begin{array}{l}\text { Ganho Médio Diário } \\
(\mathrm{kgPV} / \mathrm{d})\end{array}$ & 1,633 & 1,793 & 1,791 & 1,468 & 1,656 \\
\hline $\begin{array}{l}\text { Rendimento de Carcaça } \\
\text { (\%PV/Pcarc) }\end{array}$ & 55,76 & 55,04 & 54,85 & 55,53 & 55,16 \\
\hline $\begin{array}{l}\text { Conversão Alimentar } \\
\text { (kg MS/arroba produzida) }\end{array}$ & 133,11 & 144,48 & 137,71 & 134,33 & 136,71 \\
\hline $\begin{array}{l}\text { Cotação venda } \\
\text { com premiações (R\$/arroba) }\end{array}$ & 94,57 & 89,12 & 91,42 & 95,32 & 92,85 \\
\hline $\begin{array}{l}\text { Custo dos Produtos Vendidos } \\
\text { (R\$/cabeça) }\end{array}$ & $1.913,44$ & $1.798,53$ & $1.805,38$ & $1.818,70$ & $1.808,73$ \\
\hline Faturamento ( $\mathrm{R} \$ /$ cabeça) & $1.799,51$ & $1.748,88$ & $1.725,94$ & $1.696,70$ & $1.719,40$ \\
\hline Lucro Bruto $(\mathrm{R} \$)$ & $-2,45$ & 52,28 & 17,65 & $-25,09$ & 8,82 \\
\hline EBITDA (R\$/cabeça) & $-113,92$ & $-49,65$ & $-79,45$ & $-122,00$ & $-89,33$ \\
\hline
\end{tabular}

Negociações: Avaliação cotação de compra e quebra de peso. Dentro dos critérios de compra, os itens de maior representatividade são a cotação da arroba e a quebra de peso dos animais entre a pesagem na fazenda e o peso de entrada dos mesmos no confinamento. Quando analisado o ágio de compra, foi verificado que a média de preços praticados foi somente 2,87\% acima do valor da praça de referência no momento da aquisição, restando como única justificativa a quebra de peso como fator justificativo. Houve quebra de $11,69 \%$ entre o peso de entrada dos animais no confinamento e o peso que os mesmos foram negociados. Isto pode ser tanto por uma perda de peso no transporte, o que é razoável e compensado com um maior ganho de peso dos animais, mas também pode ser resultado de uma má avaliação dos compradores quanto ao peso dos animais.

Mercado: Estabilidade ou inversão da tendência de preços da arroba no mercado. O mercado pecuário é caracterizado por uma alteração de tendência de 
preços em que no primeiro semestre há uma tendência de baixa e, no segundo, uma valorização da cotação devido aos efeitos sazonais (Santos et al., 2006). Esta flutuação gera uma estratégia de carregamento de estoque entre períodos de em que há alteração das curvas de oferta e demanda, possibilitando assim aferir ganhos financeiros através da compra de animais no período de maior disponibilidade, e a oferta dos mesmos no período de baixa oferta.

Quando analisadas as cotações dos últimos 10 anos (Tabela 5), foi observado que em média o segundo semestre foi $6,4 \%$ mais valorizado em relação ao primeiro, entretanto, em 2012 o movimento foi inverso e houve desvalorização no segundo semestre, o que corrobora com o resultado negativo observado.

Tabela 5. Índice médio entre cotações do segundo e primeiro semestre

\begin{tabular}{lc}
\hline \multicolumn{2}{c}{ Média $2^{\circ}$ semestre $/ 1^{\circ}$ semestre. } \\
\hline 2003 & 1,06 \\
2004 & 1,03 \\
2005 & 0,94 \\
2006 & 1,13 \\
2007 & 1,19 \\
2008 & 1,13 \\
2009 & 0,96 \\
2010 & 1,23 \\
2011 & 0,99 \\
2012 & 0,99 \\
\hline Geral & 1,064
\end{tabular}

Fonte: CEPEA, 2014

Resultados projetados 2012

O modelo de planejamento proposto é concebido na forma de receber revisões mensais e anteceder um cenário de três meses (um ciclo). Isto daria ao gestor a possibilidade de definir à equipe de compra de animais quanto aos objetivos e diretrizes quanto ao padrão de animais e as condições de negociação, ou até mesmo quanto a decisão pela execução da atividade ou sua paralisação até o momento mais oportuno. O cenário considera uma posição onde compras e vendas estariam protegidas por hedge e o desempenho zootécnico é projetado sobre médias e funções matemáticas específicas (Tabela 6). 
Tabela 6. Desempenho zootécnico do segundo semestre e primeiro semestre de 2012

\begin{tabular}{|c|c|c|c|c|c|}
\hline & $\begin{array}{c}1^{0} \\
\text { Trimestre }\end{array}$ & $\begin{array}{c}2^{\circ} \\
\text { Trimestre }\end{array}$ & $\begin{array}{c}3^{\circ} \\
\text { Trimestre }\end{array}$ & $\begin{array}{c}4^{0} \\
\text { Trimestre }\end{array}$ & 2012 \\
\hline Cabeças & 935 & 2.152 & 11.479 & 6.401 & 20.967 \\
\hline Diárias $(\mathrm{R} \$)$ & 91,81 & 98,95 & 99,04 & 108,68 & 101,65 \\
\hline Peso de Entrada (kg) & 356,53 & 330,00 & 334,05 & 334,47 & 334,76 \\
\hline $\begin{array}{l}\text { Cotação compra / peso entrada } \\
\text { (R\$/arroba) }\end{array}$ & 114,10 & 104,43 & 108,12 & 111,95 & 109,20 \\
\hline Peso de Saída (kg) & 505,89 & 493,20 & 497,06 & 509,27 & 500,78 \\
\hline $\begin{array}{l}\text { Ganho Médio Diário } \\
\text { (peso vivo kg/dia) }\end{array}$ & 1,627 & 1,649 & 1,646 & 1,612 & 1,635 \\
\hline $\begin{array}{l}\text { Rendimento de Carcaça } \\
\text { (\% peso vivo/peso carcaça) }\end{array}$ & 55,10 & 55,10 & 55,10 & 55,10 & 55,10 \\
\hline $\begin{array}{l}\text { Conversão alimentar } \\
\text { (kgMS/arroba produzida) }\end{array}$ & 127,26 & 125,01 & 125,78 & 131,23 & 127,43 \\
\hline $\begin{array}{l}\text { Cotação venda com } \\
\text { premiações (R\$/arroba) }\end{array}$ & 102,24 & 94,81 & 101,17 & 100,39 & 92,86 \\
\hline $\begin{array}{l}\text { Custo dos Produtos Vendidos } \\
\text { (R\$/cabeça) }\end{array}$ & $1.969,32$ & $1.722,18$ & $1.829,63$ & $1.974,81$ & $1.869,15$ \\
\hline Faturamento (R\$/cabeça) & $1.900,10$ & $1.717,66$ & $1.847,32$ & $1.878,15$ & $1.845,77$ \\
\hline Lucro Bruto (R\$) & 23,50 & 93,73 & 115,94 & 11,27 & 122,13 \\
\hline EBITDA (R\$/cabeça) & $-69,22$ & $-4,53$ & 17,69 & $-96,66$ & $-23,38$ \\
\hline
\end{tabular}

Mesmo em uma operação em que houvesse proteção das posições, ainda assim apesar de menor prejuízo, haveria expectativa de resultados negativos, justamente pela dinâmica atípica de mercado bovino para o ano.

Contribuiu também para os resultados a perda de poder de troca entre o boi gordo e a soja e milho (Figura 6). Estas commodities são utilizadas diretamente na alimentação e balizam também o mercado de subprodutos substitutivos, encarecendo assim o custo da ração e diretamente o custo de produção. 


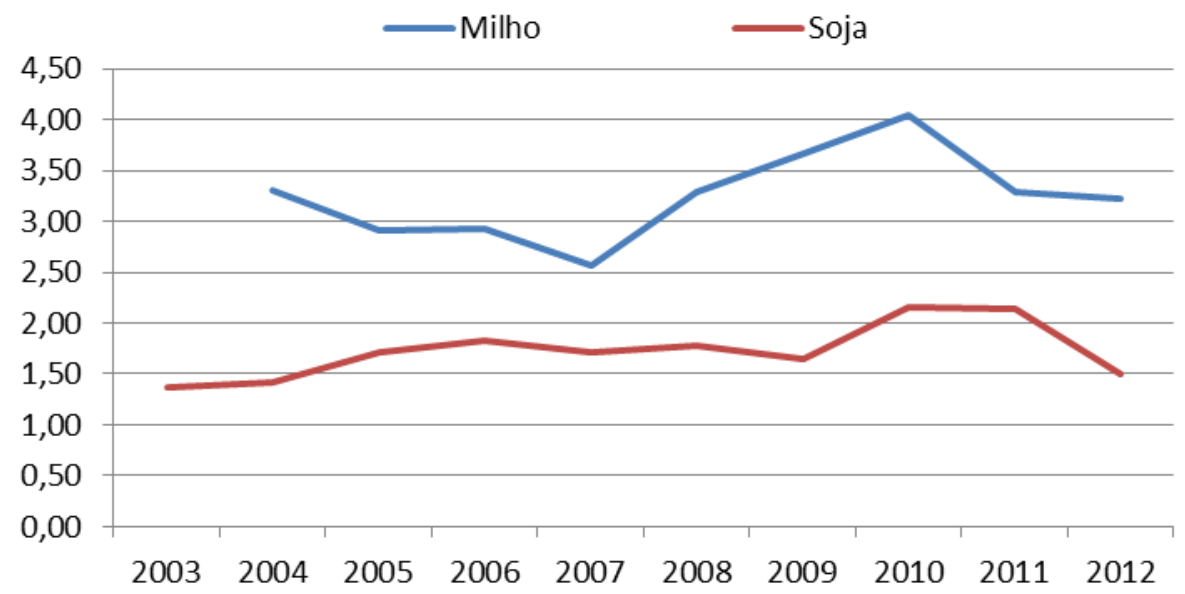

Figura 6. Relação de troca sacas de milho e soja (60 kg) / arroba Boi Gordo - Indicador Fonte: (CEPEA, 2014)

\section{Resultados Seguindo Planejamento Estratégico 2012}

Ao realizar o planejamento, foram utilizadas projeções zootécnicas e cotações para o mercado futuro tanto para a compra quanto para a venda. Porém, por haver o desconhecimento quanto ao número exato de animais adquiridos em cada período e, não haver intenção de especulação, para a compra de animais a prática de hedge não deve ser aplicada e a compra de animais deve ser realizada utilizando cotações e regras do mercado à vista.

Foram apresentados resultados onde os indicadores zootécnicos e dados de custos são os reais, mas haveria a operação de hedge na venda dos animais, além da adoção das diretrizes definidas no planejamento (Tabela 7). 
Tabela 7. Desempenho zootécnico do segundo semestre e primeiro semestre de 2012

\begin{tabular}{|c|c|c|c|c|c|}
\hline & $\begin{array}{c}10 \\
\text { Trimestre }\end{array}$ & $\stackrel{20}{\stackrel{0}{\text { Trimestre }}}$ & $\begin{array}{c}3^{\circ} \\
\text { Trimestre }\end{array}$ & $\begin{array}{c}4^{\circ} \\
\text { Trimestre }\end{array}$ & 2012 \\
\hline Cabeças & 935 & 2.152 & 11.479 & 6.401 & 20.967 \\
\hline Diárias $(\mathrm{R} \$)$ & 91,81 & 98,95 & 99,04 & 108,68 & 101,65 \\
\hline Peso de Entrada (kg) & 356,53 & 330,00 & 334,05 & 334,47 & 334,76 \\
\hline $\begin{array}{l}\text { Cotação compra /peso entrada } \\
\text { (R\$/arroba) }\end{array}$ & 108,74 & 96,02 & 102,31 & 106,50 & 103,27 \\
\hline Peso de Saída (kg) & 506,48 & 507,43 & 511,45 & 494,01 & 503,09 \\
\hline $\begin{array}{l}\text { Ganho médio diário } \\
\text { (kg peso vivo/dia) }\end{array}$ & 1,633 & 1,793 & 1,791 & 1,468 & 1,656 \\
\hline $\begin{array}{l}\text { Rendimento de carcaça } \\
\text { (\% peso vivo/ peso carcaça) }\end{array}$ & 55,76 & 55,04 & 54,85 & 55,53 & 55,38 \\
\hline $\begin{array}{l}\text { Conversão Alimentar } \\
\text { (kg matéria seca/arroba } \\
\text { produzida) }\end{array}$ & 127,85 & 134,37 & 133,54 & 136,26 & 134,20 \\
\hline $\begin{array}{l}\text { Cotação venda com } \\
\text { premiações ( } \$ \text { \$arroba) }\end{array}$ & 102,24 & 94,81 & 101,17 & 100,39 & 100,33 \\
\hline $\begin{array}{l}\text { Custo dos Produtos Vendidos } \\
\text { (R\$/cabeça) }\end{array}$ & $1.903,44$ & $1.640,55$ & $1.772,32$ & $1.879,94$ & $1.797,05$ \\
\hline Faturamento ( $\mathrm{R} \$$ /cabeça) & $1.925,14$ & $1.765,09$ & $1.892,23$ & $1.836,07$ & $1.863,07$ \\
\hline Lucro Bruto $(\mathrm{R} \$)$ & 114,42 & 224,49 & 219,94 & 65,90 & 168,74 \\
\hline EBITDA (R\$/cabeça) & 21,69 & 124,54 & 119,91 & $-43,87$ & 66,07 \\
\hline
\end{tabular}

Para buscar a maior amplitude entre as cotações de compra e venda (que apesar de pequenas para o ano de 2012, em algumas ocasiões ocorreram) foram explorados tanto os pesos de entrada quanto a forma de negociação - entre compra e parceria. Além disso, a realização de hedge no momento em que os animais adentravam no confinamento garantiram as cotações de venda esperadas no momento da compra.

Desta forma, o resultado estimado foi inverso ao possivelmente realizável, em que foi possível aferir EBITDA de $\mathrm{R} \$ 66,07$ por cabeça abatida. Isto se deu principalmente por ganho de produtividade - 6,97 arrobas contra 7,41 arrobas decorrente do menor peso de entrada, e pela maior amplitude da relação entre preço de venda e compra - 1,0136 contra 1,0996.

\section{Conclusão}

A análise de projeções para 2012 indicaria ao gestor que seria um ano de desafios para a atividade, em que a atividade serviria apenas para absorver parte do custo fixo. Esta informação poderia ajudar o gestor a definir a melhor estratégia quanto a alocação de investimentos, redução de custos e até mesmo quanto a decisão de confinar ou não. A falta de visão geral sobre as perspectivas de negócio em curto prazo podem levar a graves prejuízos e até mesmo comprometer a existência da empresa. 
A dificuldade em realizar planejamento estratégico da atividade não decorre da incapacidade dos gestores, mas sim da alta complexidade do mercado associada a carência em sistemas de informação eficientes e dinâmicos, capazes de subsidiar os gestores com informações em tempo hábil para tomadas de decisões eficientes.

\section{Referências}

Alexandratos, N.; Bruinsma, J. 2012. World agriculture towards 2030/2050. Food and Agriculture Organization of the United Nations.

Azevêdo, J.A.G.; Filho, S.C.V.; Pina, D.S.; Valadares, R.F.D.; Detmann, E. 2010. Predição de consumo de matéria seca por bovinos de corte em confinamento. BR-Corte 1-12.

Bolsa de Mercadorias e Futuros [BM\&F]. 2014. Boi Gordo com Liquidação Financeira. BM\&FBOVESPA. Disponível em: http://www.bmfbovespa.com.br/shared/iframe.aspx?altura=1200\&idioma=ptbr\&url=www.bmf.com.br/bmfbovespa/pages/contratos 1/contratosProdutosAgropecuari os1.asp. Acessado em: 03 jun. 2014.

BRASIL. 1990. Secretaria Nacional de Defesa Agropecuária. Secretaria de Inspeção de Produto Animal. Padronização de cortes de carne bovina. Brasília: MA/SNAD/SIPA. $98 \mathrm{p}$.

Centro de Estudos Avançados em Economia Aplicada [CEPEA]. 2014. Indicador Boi. Disponível em: http://cepea.esalq.usp.br/boi/\#. Acessado em: 20 jun. 2014.

Crozzati, J. 2003. Planejamento estratégico e controladoria: Um modelo para potencializar a contribuição das áreas da organização. ConTexto 3: 1-20.

Empresa Brasileira de Pesquisa Agropecuária [EMBRAPA]. 2014. Embrapa Gado de Corte. Problemas no Confinamento do Gado de Corte. Disponível em: http://www.cnpgc.embrapa.br/publicacoes/doc/doc64/06problemasconfinamento.html. Acesso em: 01 de Jun. 2014.

European Comission 2014. 2007-2013. Animal Health and Welfare. TRACES. 20072013. Disponível em: http://ec.europa.eu/food/animal/diseases/traces/index_en.htm. Acesso em: 05 jun. 2014.

Gaio, L.E.; Júnior, L.G. de C; Oliveira, A.R. 2005. Causalidade e elasticidade na transmissão de preço do boi gordo entre regiões do Brasil e a bolsa de mercadorias \& futuros (BMF). Organizações Rurais \& Agroindustriais 7(3): 282-297.

Hull. J.C. 2005. Fundamentos dos mercados futuros e de opções. 4. ed. São Paulo: Bolsa de Mercadorias e Futuros.

Jorge, A.M.; Fontes, C.A.A.; Freitas, J.A. 1997. Rendimento da carcaça e de diferentes cortes básicos de bovinos e bubalinos, abatidos em diferentes estádios de maturidade. Revista Brasileira de Zootecnia 26(5):1048-1054. 
Neto, O.J. de O.; Figueiredo, R.S. 2008. Efetividade das operações do boi gordo no mercado futuro da BM\&F para o Estado de Goiás.

Portal do investidor. 2014. Mercado Futuro. [Online]. Disponível em: http://www.cvm.gov.br/port/protinv. Acessado em: 20 de Março 2014.

Preston, T. R.; Willis, M. B. 1970.Intensive beef production. s.I. : Pergamon Press.

Santos, J.C.; Gomes, S.C. 2006. Padrões sazonal e cíclico para preço de boi gordo no estado de São Paulo. 1976-2004. In: CONGRESSO BRASILEIRO DE ECONOMIA E SOCIOLOGIA RURAL, 44, 2006, Fortaleza. Anais... Fortaleza: SOBER/BNB, 2006. 